\title{
PENINGKATAN KEMAMPUAN SPASIAL SISWA MELALUI PENERAPAN PEMBELAJARAN MATEMATIKA REALISTIK
}

\author{
Edi Syahputra \\ FMIPA Universitas Negeri Medan \\ email: edisyahputra21@yahoo.com
}

\begin{abstract}
Abstrak: Fokus penelitian ini adalah untuk mengidentifikasi peningkatan kemampuan spasial siswa sebagai dampak penerapan pembelajaran Matematika realistik. Penelitian ini adalah penelitian eksperimen, melibatkan seluruh siswa kelas delapan sekolah pada peringkat baik dan sedang. Sampel penelitian ini terdiri atas 152 orang siswa. Instrumen yang digunakan dalam penelitian ini adalah tes kemampuan spasial. Data dianalisis dengan menggunakan uji Mann-Whitney U, analisis korelasi, 1way dan 2-way ANOVA dengan menggunakan uji post hoc. Berdasarkan hasil analisis data, dapat disimpulkan bahwa kemampuan spasial siswa yang diajar menggunakan pendekatan Matematik realistik lebih baik daripada kemampuan spasial siswa yang diajar dengan pendekatan konvensional. Ada interaksi antara pendekatan pembelajaran dan peringkat sekolah terhadap peningkatan kemampuan spasial siswa.
\end{abstract}

Kata Kunci: kemampuan spasial, pembelajaran matematika, matematika realistik

\section{IMPROVEMENT OF THE STUDENTS' SPATIAL ABILITY THROUGH THE IMPLEMENTATION OF REALISTIC MATHEMATICS TEACHING}

Abstract: The focus of this study was to identify the improvement of students' spatial ability as an impact of realistic mathematics education approach. This study was an experimental research, involving the eighth grade students of the good level and middle level schools. The sample of this study consisted of 152 students. The instruments used in this study were the spatial ability test. The data were analyzed by using Mann-Whitney $\mathrm{U}$ test, t-test, $\mathrm{r}$ correlative analysis, 1-way and 2-way ANOVA with the post hoc test. Based on the result of the data analysis it can be concluded that the students' spatial ability under Realistic Mathematics Education approach was better than that of the students taught using the conventional approach. There was an interaction between the instructional approach and the school level toward the enhancement of students' spatial ability.

Keywords: spatial ability, mathematics education, realistic mathematics

\section{PENDAHULUAN}

Konsep tentang berpikir spasial cukup menarik untuk dibahas mengingat banyak penelitian sebelumnya yang menemukan bahwa anak menemukan banyak kesulitan untuk memahami objek atau gambar bangun geometri. Berpikir spasial merupakan kumpulan dari keterampilan-keterampilan kognitif, yang terdiri dari gabungan tiga unsur yaitu konsep keruangan, alat representasi, dan proses penalaran (National Academy of Science, 2006:12).
Kemampuan spasial merupakan satu konsep dalam Berpikir spasial. Linn dan Petersen (National Academy of Science, 2006:44) mengelompokkan kemampuan spasial ke dalam tiga kategori yaitu: (1) persepsi spasial, (2) rotasi mental, dan (3) visualisasi spasial. Dipandang dari konteks matematika khususnya geometri ternyata kemampuan spasial sangat penting untuk ditingkatkan, hal ini mengacu dari hasil penelitian berikut ini. Dalam National Academy of Science (2006:45) dikeemukakan bahwa setiap siswa harus berusaha mengem- 
bangkan kemampuan dan penginderaan spasialnya yang sangat berguna dalam memahami relasi dan sifat-sifat dalam geometri untuk memecahkan masalah matematika dan masalah dalam kehidupan sehari-hari.

Giaquinto (2007:15) mengemukakan bahwa persepsi dari suatu objek atau gambar dapat dipengaruhi secara ekstrim oleh orientasi objek tersebut. Untuk dapat mengenali suatu objek/gambar dengan tepat diperlukan kemampuan spasial. Hannafin, Truxaw, Jennifer, dan Yingiie (2008:148), dalam penelitiannya menemukan bahwa siswa dengan kemampuan spasial yang tinggi secara signifikan lebih mampu dalam matematikanya. Penelitian lainnya telah menunjukkan bahwa kemampuan kognitif seperti kemampuan spasial diprediksi berhasil dalam lingkungan belajar tertentu, khususnya dalam geometri. Kemampuan spasial yang baik akan menjadikan siswa mampu mendeteksi hubungan dan perubahan bentuk bangun geometri.

Jika dipandang dari konteks kehidupan sehari-hari kemampuan spasial juga perlu ditingkatkan, hal ini mengacu dari pendapat Barke dan Engida (2001:237) yang mengemukakan bahwa kemampuan spasial merupakan faktor kecerdasan utama yang tidak hanya penting untuk matematika dan science, tetapi juga perlu untuk keberhasilan dalam banyak profesi. Gadner (Republika on line, 2008) yang pada intinya menulis bahwa anak membutuhkan kemampuan spasial dalam aktivitas bereksplorasi misalnya ketika anak melukis, mewarnai, menempel, bermain kertas lipat, dll. Seorang pilot juga sangat membutuhkan kemampuan spasial yang tinggi untuk mengetahui dengan baik dimana tanah/lapangan selama dia bermanuver. Demikian juga seorang nakoda kapal laut pasti sangat membutuhkan kemampuan spasial yang tinggi dalam menjalankan tugasnya.

Dalam konteks hubungan lintas ilmu/ bidang studi maka kemampuan spasial sangat dibutuhkan. Strong dan Roger (2002:2) mengemukakan bahwa dalam teknologi industri kemampuan spasial sangat bermanfaat dalam penerapan seperti simulasi, multi media dan pemodelan. Alias, Black, dan Gray (2002:1) me- ngemukakan bahwa dibutuhkan kemampuan spasial yang baik untuk dapat belajar dan memecahkan masalah-masalah teknik. Pendapat yang hampir sama juga dikemukakan oleh Rafi dan Samsudin (2007:63) yang menemukan dalam penelitiannya di Malaysia bahwa hampir semua topik dalam "menggambar mesin" sangat membutuhkan kemampuan spasial yang tinggi. Dalam National Academy of Science (2006:46) dikatakan bahwa banyak bidang ilmu yang membutuhkan kemampuan spasial dalam penerapan ilmu tersebut antara lain astronomi, pendidikan, geografi, geosciences, dan psichologi. Nemeth (2007:123) dalam penelitiannya menemukan pentingnya kemampuan spasial yang dengan nyata sangat dibutuhkan pada ilmu-ilmu teknik dan matematika khususnya geometri. Kemampuan ini tidak ditemukan secara genetik tetapi sebagai hasil proses belajar yang panjang.

Dalam konteks kurikulum, NCTM (2000: 29) telah menentukan 5 standar isi dalam standar matematika, yaitu bilangan dan operasinya, pemecahan masalah, geometri, pengukuran, dan peluang dan analisis data. Dalam geometri terdapat unsur penggunaan visualisasi, penalaran spasial dan pemodelan. Hal ini menunjukkan bahwa kemampuan spasial merupakan tuntutan kurikulum yang harus diakomodasi dalam pembelajaran di kelas. Dalam kurikulum nasional di Indonesia, dari tingkat sekolah dasar sampai perguruan tinggi siswa/ mahasiswa dituntut untuk dapat menguasai materi geometri bidang dan geometri ruang yang notabene juga membutuhkan kemampuan spasial.

Demikian pentingnya kemampuan spasial ini sehingga kita semua terutama para guru dituntut untuk memberikan perhatian yang lebih dari cukup agar kemampuan spasial diajarkan dengan sungguh-sungguh sesuai dengan amanat kurikulum. Guru dapat menggunakan pendekatan pembelajaran yang cocok dan secara teoretis dapat meningkatkan hasil belajar siswa.

Pendekatan Pendidikan Matematika Realistik bertitik tolak dari hal-hal yang nyata bagi siswa, menekankan ketrampilan proses Berpikir dan bekerja dalam matematika, berdiskusi sesama teman dan berkolaborasi sehingga mereka 
dapat menemukan sendiri dan pada akhirnya menggunakan matematika untuk menyelesaikan masalah secara individu maupun kelompok. Pada pendekatan ini peran guru tak lebih dari seorang fasilitator, moderator atau evaluator sementara siswa Berpikir, mengkomunikasikan penalarannya dan berkolaborasi dengan orang lain.

Secara umum, pendekatan Pendidikan Matematika Realistik terdiri dari lima karakteristik yaitu: (1) penggunaan "konteks nyata" (2) penggunaan "model" (3) pengaitan dalam dan antar topik matematika; (4) penggunaan metode interaktif dan (5) menghargai variasi jawaban dan kontribusi siswa.

Anh (2006:183) dalam penelitiannya mengajar geometri di Middle School Vietnam yang menerapkan pembelajaran matematika realistik menemukan bahwa siswa terdorong untuk membangun pengetahuan mereka secara gradual dari informal ke formal. Keaktifan dan kreativitas siswa meningkat selama pembelajaran menggunakan Realistic Mathematics Education (RME). Pembelajaran menggunakan RME memungkinkan siswa untuk "menemukan" kembali pengetahuan matematika dan sebahagian besar siswa aktif berpartisipasi dalam diskusi sesama mereka. Anh Le mere-komendasikan untuk mempertimbangkan pengajaran geometri menggunakan RME di Vietnam. Berikutnya Anh Le melaporkan bahwa penggunaan pembelajaran RME di Vietnam secara signifikan meningkatkan prestasi matematika siswa, khususnya siswa di daerah perkotaan mempunyai prestasi lebih tinggi dari siswa di daerah pedesaan dan daerah terpencil. Pembelajaran menggunakan RME pada kelompok siswa berkemampuan rendah sangat dianjurkan, karena siswa berkesempatan untuk menggunakan matematika informal.

Arifin (2008:174) dalam penelitiannya di kelas IV Sekolah Dasar menemukan bahwa siswa yang mengikuti pembelajaran matematika realistik dengan strategi kooperatif mengalami peningkatan dalam hal motivasi berprestasi, kemampuan pemecahan masalah matematika, hasil belajar matematika, aktivitas dalam kegiatan belajar matematika dan ketuntasan be- lajar siswa dibandingkan jika siswa mengikuti pembelajaran secara konvensional.

Sulastri (2009:123) dalam penelitiannya di SMP se kabupaten Bandung menemukan bahwa siswa yang mengikuti pembelajaran menggunakan pendekatan pendidikan matematika realistik berkategori lebih baik dalam hal kemampuan komunikasi matematis, sikap positip terhadap pembelajaran matematika, keaktifan selama kegiatan pembelajaran berlangsung, dibandingkan jika siswa mengikuti pembelajaran biasa.

Eriadi (2008:125) dalam penelitiannya di SMP menemukan bahwa terdapat peningkatan kemampuan pemahaman geometri siswa yang mengikuti pembelajaran menggunakan pendekatan pendidikan matematika realistik. Demikian juga aktivitas dan respon siswa lebih baik jika mereka mengikuti pembelajaran menggunakan pendekatan pendidikan matematika realistik, dibandingkan jika mereka mengikuti pembelajaran secara konvensional. Asmida (2009:142) dalam penelitiannya di SMP menemukan bahwa siswa yang mengikuti pembelajaran pendidikan matematika realistik mendapatkan hasil yang lebih baik dalam hal kemampuan penalaran matematis, peningkatan kemampuan komunikasi matematis, prestasi siswa (kelompok rendah, sedang dan tinggi) dan sikap positip terhadap matematika dibandingkan jika mereka mendapatkan pembelajaran biasa.

Hidayat (2009:140) dalam penelitiannya di SMP menemukan bahwa siswa yang diajar dengan pendekatan matematika realistik memperoleh hasil yang lebih baik dalam hal kemampuan komunikasi matematis, peningkatan kemandirian belajar matematika, keaktifan siswa, dibandingkan jika siswa mengikuti pembelajaran langsung.

Di samping diperlukan pendekatan pembelajaran yang tepat agar mendapatkan hasil pembelajaran yang maksimal, maka sarana dan prasarana mempunyai peran yang signifikan untuk meningkatkan kemampuan spasial siswa setelah suatu pembelajaran selesai dilaksanakan. Untuk meningkatkan kemampuan spasial siswa dapat digunakan perangkat keras kom- 
puter dan perangkat lunak seperti geometri sketchpad dan geometri cabri. Penggunaan komputer dapat membantu pembelajaran agar siswa mempunyai pemahaman dan penguasaan konsep yang tepat dari materi yang dipelajarinya.

Penelitian ini menawarkan suatu strategi pembelajaran untuk meningkatkan kemampuan spasial siswa dengan menerapkan pendekatan Pendidikan Matematika Realistik pada topik geometri dengan bantuan komputer khususnya program cabri-3D. Strategi ini dilakukan dengan alasan bahwa siswa dapat lebih aktif dan bebas menuangkan ide-idenya serta dapat menikmati pembelajaran matematika apabila pembelajaran tersebut dilaksanakan dengan bantuan komputer. Chacon (2008:18) mengemukakan bahwa siswa menunjukkan motivasi yang tinggi belajar metematika dengan bantuan komputer dan mereka menikmati situasi belajar dengan gembira.

Penerapan pembelajaran Matematika Realistik pada topik geometri dengan bantuan komputer khususnya program cabri 3-D dilakukan dengan alasan bahwa lebih 50\% siswa memandang matematika sebagai pelajaran hafalan (Schackow, 2005: 47) Selain itu, Olson (Schackow, 2005:49) mengemukakan kebanyakan siswa kelas geometri tidak menyenangi matematika dan $40 \%$ dari mereka frustrasi. Tobias (Johnson, 2006:18) menyatakan siswa paranoid dan cemas pada matematika. Dengan penerapan Pembelajaran Matematika Realistik pada topik geometri dengan bantuan komputer khususnya program cabri 3D, siswa dapat memanipulasi sendiri bangun ruang geometri pada layar monitor komputernya, siswa dapat memutar atau membalik gambar sekehendaknya. Kegiatan ini cenderung tidak mengharuskan siswa menghafal. Siswa belajar dengan pemahaman yang dibentuk dari pengalaman mereka memanipulasi gambar bangun geometri ruang tersebut sekehendak mereka.

\section{METODE}

Penelitian ini merupakan penelitian eksperimen quasi dengan rancangan penelitian menggunakan kelompok kontrol pretes-postes (pretest-posttest-control group design) (Ruseffendi, 2005:52). Populasi Penelitian ini adalah seluruh siswa SMP di Medan. Sampel penelitian ditentukan menggunakan teknik sampel berstrata, terdiri dari satu sekolah kategori baik dan satu sekolah kategori sedang. Pada setiap kategori sekolah terpilih, diambil dua kelas VIII paralel, satu kelas sebagai kelas eksperimen yang mendapat pembelajaran matematika realistik pada topik geometri dengan bantuan komputer khususnya program cabri-3D. dan kelas lainnya sebagai kelas kontrol mendapat pembelajaran secara konvensional.

Penelitian ini melibatkan variabel bebas dan variabel terikat. Variabel bebasnya adalah pembelajaran Matematika Realistik dengan bantuan komputer dan pembelajaran secara konvensional. Variabel terikat adalah kemampuan spasial. Selain itu dilibatkan juga variabel kontrol yaitu kemampuan awal matematika siswa (tinggi, menengah, dan rendah) dan kategori sekolah (baik, sedang). Instrumen yang digunakan dalam penelitian ini terdiri dari lembar observasi, lembar kerja siswa, dan tes tulis kemampuan spasial. Data peningkatan kemampuan spasial siswa dianalisis berdasarkan pada pendekatan pembelajaran, kategori sekolah (baik, sedang) dan kemampuan awal matematika (KAM) siswa (tinggi, menengah, rendah).

Data dianalisis dengan membandingkan gain ternormalisasi (N-Gain) dari kemampuan spasial siswa kelas eksperimen dan gain ternormalisasi kemampuan spasial siswa kelas kontrol menggunakan analisis varian. Selanjutnya dilakukan uji lanjut (Post Hoc Test) untuk mengetahui pasangan kelompok KAM (tinggi, menengah, rendah) yang paling dominan mempengaruhi peningkatan kemampuan spasial (KS) siswa. Pengolahan data dilakukan dengan bantuan program SPSS versi 17,0

\section{HASIL DAN PEMBAHASAN}

Pada Tabel 1 ditunjukkan hasil analisis deskriptif data kemampuan spasial (KS) siswa berdasarkan kategori sekolah dan pendekatan pembelajaran yang memperlihatkan bahwa sebelum pembelajaran dilaksanakan pada sekolah kategori baik, rata-rata kemampuan spasial 
(KS) siswa pada pendekatan pembelajaran matematika realistik dan pembelajaran secara konvensional relatif sama yaitu 14,72 dan 13,42. Demikian juga pada sekolah kategori sedang rata-rata kemampuan spasial mereka juga relatif sama yaitu 6,05 dan 4,50.

Setelah pembelajaran selesai dilaksanakan terjadi perubahan kemampuan spasial (KS) siswa baik di sekolah kategori baik maupun pada sekolah kategori sedang. Pada sekolah kategori baik rata-rata kemampuan spasial (KS) siswa yang mendapat pembelajaran matematika realistik menjadi 34,69 terjadi peningkatan sebesar 0,55. Sedangkan yang mendapat pembelajaran secara konvensional menjadi
21.11 terjadi peningkatan sebesar 0,22. Pada sekolah kategori sedang, rata-rata kemampuan spasial (KS) siswa yang mendapat pembelajaran matematika realistik menjadi 14,28 terjadi peningkatan sebesar 0,19 sedangkan siswa yang mendapat pembelajaran secara konvensional rata-rata kemampuan spasial (KS) mereka menjadi 11,80 atau peningkatan sebesar 0,16 .

Pada Gambar 1. dapat dilihat bahwa peningkatan KS siswa lebih tinggi pada sekolah kategori baik. Fenomena ini menunjukkan bahwa peran pendekatan pembelajaran Matematika Realistik lebih dominan pada sekolah kategori baik.

\section{Tabel 1. Rekapitulasi Data Kemampuan Spasial (KS) Siswa Berdasarkan Kategori Sekolah}

\begin{tabular}{|c|c|c|c|c|c|c|c|}
\hline \multirow{3}{*}{$\begin{array}{l}\text { Kategori } \\
\text { Sekolah }\end{array}$} & \multirow{3}{*}{ Deskripsi } & \multicolumn{6}{|c|}{ Pendekatan Pembelajaran } \\
\hline & & \multicolumn{3}{|c|}{ Matematika Realistik } & \multicolumn{3}{|c|}{ Secara Konvensional } \\
\hline & & Pretes & Postes & $\mathrm{N}$-Gain & Pretes & Postes & N-Gain \\
\hline \multirow{3}{*}{ Baik (B) } & $\mathrm{N}$ & 36 & 36 & 36 & 36 & 36 & 36 \\
\hline & Rata-rata & 14,72 & 34,69 & 0,55 & 13.42 & 21.11 & 0,22 \\
\hline & $\begin{array}{l}\text { Simpangan } \\
\text { Baku }\end{array}$ & 5,42 & 4,99 & 0,16 & 3.53 & 5.68 & 0,11 \\
\hline \multirow{3}{*}{ Sedang (S) } & $\mathrm{N}$ & 40 & 40 & 40 & 40 & 40 & 40 \\
\hline & Rata-rata & 6,05 & 14,28 & 0,19 & 4,50 & 11,80 & 0,16 \\
\hline & $\begin{array}{l}\text { Simpangan } \\
\text { Baku }\end{array}$ & 4,22 & 8,13 & 0,14 & 2,52 & 6,47 & 0,13 \\
\hline
\end{tabular}

Skor Maksimal Ideal KS adalah 50

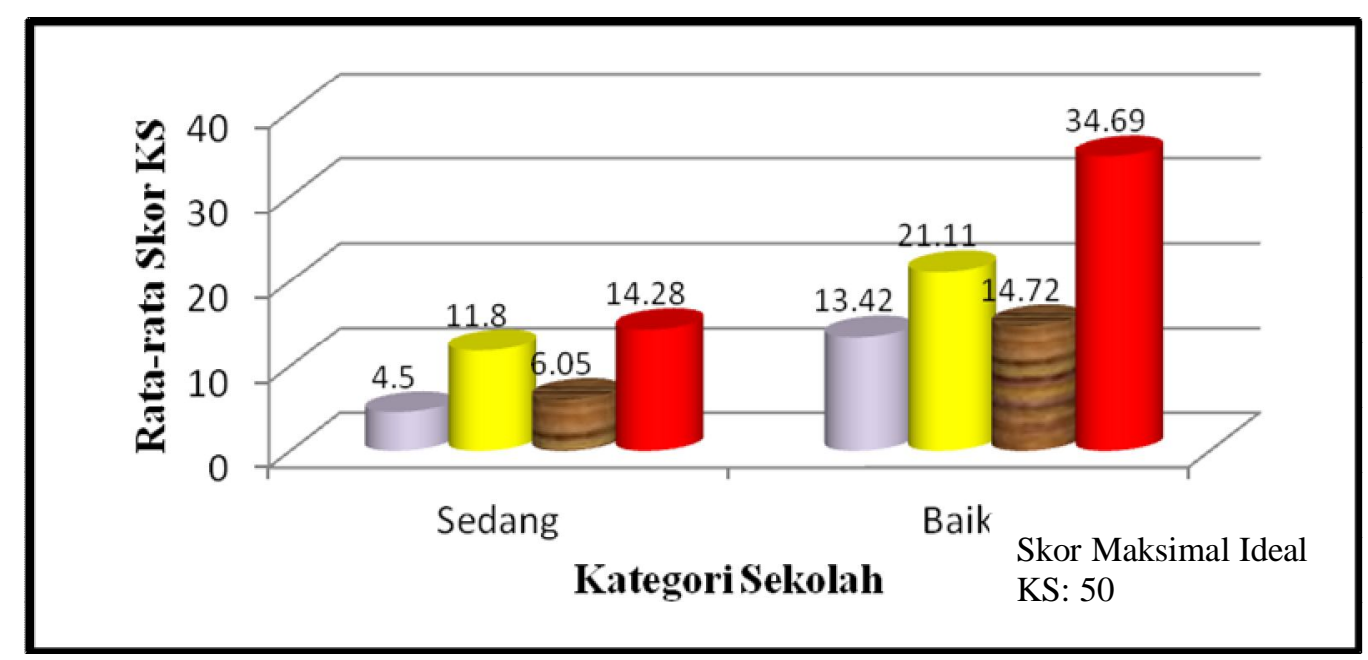

Gambar 1. Skor Kemampuan Spasial (KS) Siswa Ditinjau dari Kategori Sekolah dan Pendekatan Pembelajaran 
Pada Gambar 1. dapat dilihat bahwa peningkatan KS siswa lebih tinggi pada sekolah kategori baik. Fenomena ini menunjukkan bahwa peran pendekatan pembelajaran Matematika Realistik lebih dominan pada sekolah kategori baik.

Peningkatan Kemampuan Spasial (KS) Ditinjau dari Kemampuan Awal Matematik (KAM) dan Pendekatan Pembelajaran

Pada Tabel 2 ditunjukkan hasil analisis deskriptif data kemampuan spasial (KS) siswa berdasarkan KAM dan pendekatan pembelajaran. Kemampuan spasial (KS) siswa dari kelompok KAM tinggi sebelum mendapatkan pembelajaran relatif sama yaitu 12,36 dan 11,33. Namun setelah mendapatkan pembelajaran kemampuan spasial (KS) mereka meningkat masing-masing menjadi 29,45 dan 20,78 terjadi peningkatan masing-masing sebesar 0,46 dan 0,26.

Kemampuan spasial (KS) siswa dari kelompok KAM menengah sebelum mendapatkan pembelajaran relatif sama yaitu 10,26 dan 8,57 . Setelah mendapatkan pembelajaran kemampuan spasial (KS) mereka meningkat masing-masing menjadi 24,31 dan 15,98 terjadi peningkatan masing-masing sebesar 0,37 dan 0,18 .

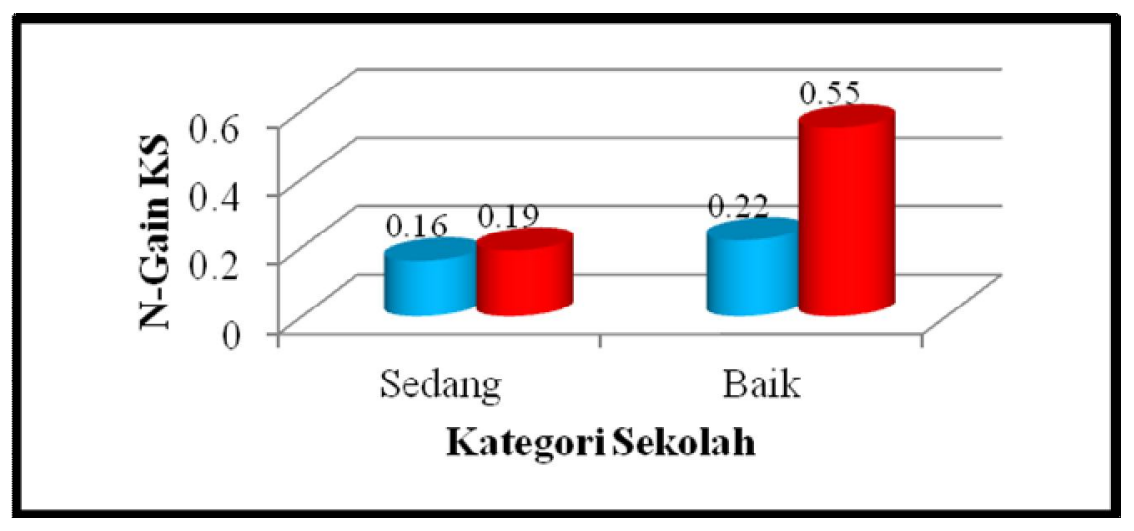

Gambar 2. N-Gain Kemampuan Spasial (KS) Siswa Ditinjau dari Kategori Sekolah dan Pendekatan Pembelajaran

Tabel 2. Rekapitulasi Kemampuan Spasial (KS) Siswa Berdasarkan Kemampuan Awal Matematik (KAM) dan Pendekatan Pembelajaran

\begin{tabular}{llrrrrrr}
\hline \multirow{2}{*}{$\begin{array}{c}\text { Kelompok } \\
\text { KAM }\end{array}$} & \multicolumn{1}{c}{$\begin{array}{c}\text { Deskripsi } \\
\text { KS }\end{array}$} & \multicolumn{6}{c}{ Pendekatan Pembelajaran } \\
\cline { 3 - 8 } Tinggi & .n & Matematika Realistik & Secara Konvensional \\
\cline { 2 - 8 } & Rata-rata & 12,36 & 29,45 & 0,46 & 11,33 & 20,78 & 0,26 \\
& Simpangan Baku & 1,96 & 8,35 & 0,21 & 7,02 & 9,96 & 0,14 \\
\multirow{3}{*}{ Menengah } & .n & 58 & 58 & 58 & 63 & 63 & 63 \\
& Rata-rata & 10,26 & 24,31 & 0,37 & 8,57 & 15,98 & 0,18 \\
& Simpangan Baku & 6,58 & 12,00 & 0,24 & 5,16 & 7,13 & 0,12 \\
\multirow{3}{*}{ Rendah } & .n & 7 & 7 & 7 & 4 & 4 & 4 \\
& Rata-rata & 5,86 & 12,29 & 0,18 & 5,25 & 9,50 & 0,10 \\
& Simpangan Baku & 8,76 & 13,85 & 0,19 & 3,30 & 5,45 & 0,07 \\
\hline
\end{tabular}

Skor Maksimal Ideal adalah 50 
Data ini juga menunjukkan terjadi peningkatan kemampuan spasial (KS) yang lebih besar di kelompok KAM menengah yang mendapat pembelajaran Matematika Realistik dibandingkan peningkatan kemampuan spasial (KS) siswa di kelompok KAM tinggi yang mendapatkan pembelajaran secara konvensional. Demikian juga peningkatan kemampuan spasial (KS) siswa pada KAM rendah yang mendapat pembelajaran Matematika Realistik dapat menyamai peningkatan kemampuan spasial (KS) siswa pada KAM menengah yang mendapat pembelajaran secara konvensional.

Pada Gambar 3 ditunjukkan grafik hasil pretes dan postes dari kemampuan spasial siswa pada kedua pendekatan pembelajaran ditinjau dari kelompok KAM siswa. Data di atas menunjukkan bahwa setelah pembelajaran Matematika Realistik diberikan, kelompok KAM menengah lebih diuntungkan dibandingkan dengan kelompok KAM tinggi dan kelompok KAM rendah. N-gain pada kelompok KAM menengah siswa yang mendapat pembelajaran Matematika Realistik lebih dari 2 kali lipat dari $\mathrm{N}$-gain kelompok KAM menengah siswa yang diajar secara konvensional. Gambar 4 dapat mempertegas bahwa kelompok KAM menengah dan KAM rendah lebih diuntungkan setelah pembelajaran Matematika Realistik.

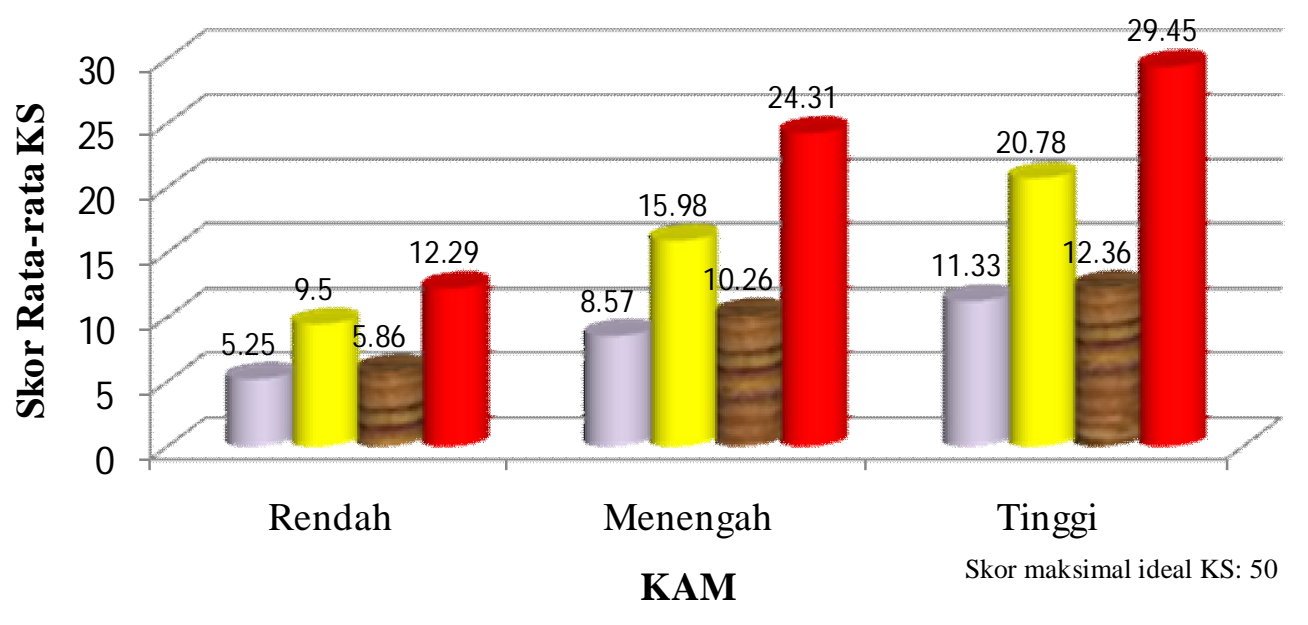

Gambar 3. Kemampuan Spasial (KS) Siswa Ditinjau dari Kemampuan Awal Matematika (KAM) dan Pendekatan Pembelajaran

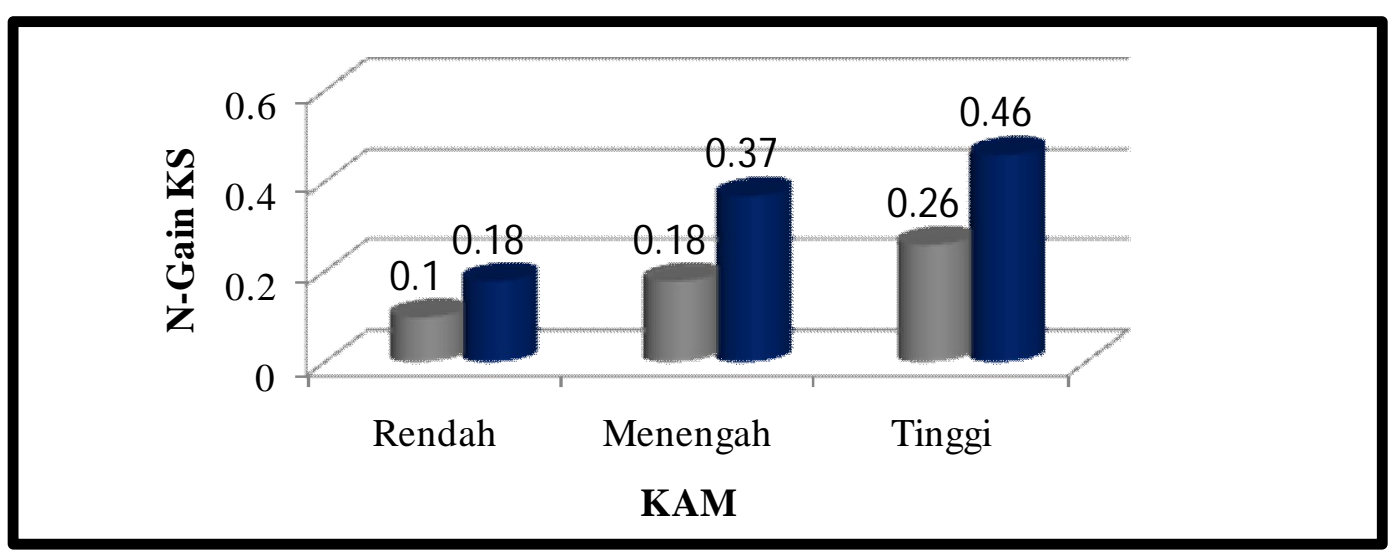

Gambar 4. N-Gain Kemampuan Spasial (KS) Siswa Ditinjau dari Kemampuan Awal Matematika (KAM) dan Pendekatan Pembelajaran 


\section{Interaksi antara Pendekatan Pembelajaran dan Kategori Sekolah terhadap Peningkatan KS Siswa}

Pada Tabel 3 ditunjunjukkan uji perbedaan dan interaksi antara pendekatan pembelajaran dan kategori sekolah terhadap peningkatan kemampuan spasial siswa.

Jadi, dapat dilihat bahwa terdapat perbedaan peningkatan kemampuan spasial (KS) siswa yang signifikan berdasarkan pendekatan pembelajaran, berdasarkan kategori sekolah dan berdasarkan interaksi antar keduanya. Dengan perkataan lain pendekatan pembelajaran memberikan pengaruh terhadap peningkatan kemampuan spasial (KS) siswa, demikian juga kategori sekolah juga memberikan pengaruh terhadap peningkatan kemampuan spasial (KS) siswa. Pada Tabel 3 dapat juga dilihat bahwa terdapat interaksi antara pendekatan pembelajaran dan kategori sekolah terhadap peningkatan kemampuan spasial (KS) siswa. Gambar 5. Merepresentasikan secara visual interaksi tersebut.

Pada Gambar 5 terlihat bahwa selisih peningkatan kemampuan spasial (KS) siswa antara yang mendapat pembelajaran Matematika Realistik dan siswa yang mendapat pembelajaran secara konvensional pada kategori sekolah baik lebih besar dibandingkan dengan selisih peningkatan kemampuan spasial (KS) siswa pada sekolah kategori sedang. Hal ini menunjukkan bahwa pendekatan pembelajaran Mate- matika Realistik lebih tepat diterapkan pada siswa sekolah kategori baik dari pada siswa di sekolah kategori sedang.

\section{Interaksi antara Pendekatan Pembelajaran dan Kemampuan Awal Matematika (KAM) terhadap Peningkatan Kemampuan Spasial (KS) Siswa}

Pada Tabel 4 ditunjukkan uji perbedaan dan interaksi antara pendekatan pembelajaran dan kelompok KAM terhadap peningkatan kemampuan spasial siswa yang memperlihatkan bahwa terdapat perbedaan peningkatan kemampuan spasial siswa yang signifikan berdasarkan pendekatan pembelajaran dan berdasarkan kelompok KAM. Dengan perkataan lain pendekatan pembelajaran memberikan pengaruh terhadap peningkatan kemampuan spasial (KS) siswa, demikian juga kelompok KAM juga memberikan pengaruh terhadap peningkatan kemampuan spasial (KS) siswa. Pada Tabel 4 dapat juga dilihat bahwa tidak terdapat interaksi antara pendekatan pembelajaran dan kategori sekolah terhadap peningkatan kemampuan spasial (KS) siswa.

Secara visual Gambar 6 menunjukkan peningkatan kemampuan spasial (KS) siswa ditinjau dari pendekatan pembelajaran, kelompok KAM siswa serta tidak adanya interaksi antara pendekatan pembelajaran dan kelompok KAM terhadap kemampuan spasial (KS) siswa.

Tabel 3. Uji Perbedaan dan Interaksi antara Pendekatan Pembelajaran dan Kategori Sekolah terhadap Peningkatan Kemampuan Spasial (KS) Siswa

\begin{tabular}{ccccccc}
\hline Sumber Variasi & $\begin{array}{c}\text { Jumlah } \\
\text { Kuadrat }\end{array}$ & $\mathrm{db}$ & $\begin{array}{c}\text { Rata-rata } \\
\text { Kuadrat }\end{array}$ & $\mathrm{F}$ & Sig & Keputusan \\
\hline Pendekatan Pembelajaran & 1,299 & 1 & 1,299 & 67,56 & 0,00 & Tolak $\mathrm{H}_{\mathrm{o}}$ \\
& 1,65 & 1 & 1,65 & 85,89 & 0,00 & ${\text { Tolak } \mathrm{H}_{\mathrm{o}}}$ \\
Kategori Sekolah & 0,91 & 1 & 0,91 & 47,44 & 0,00 & Tolak $\mathrm{H}_{\mathrm{o}}$ \\
Interaksi & 2,85 & 148 & 0,02 & & & \\
Error & 18,21 & 152 & & & & \\
\hline Total & & &
\end{tabular}

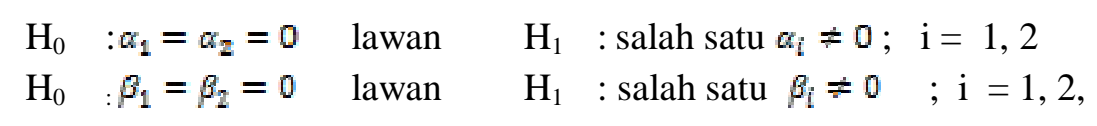


$\mathrm{H}_{0}: \alpha_{i} \beta_{j}=0 \quad$ lawan $\quad \mathrm{H}_{1}$ : paling sedikit satu pasangan $: \alpha_{i} \beta_{j} \neq 0 ; \quad \mathrm{i}, \mathrm{j}=1,2$

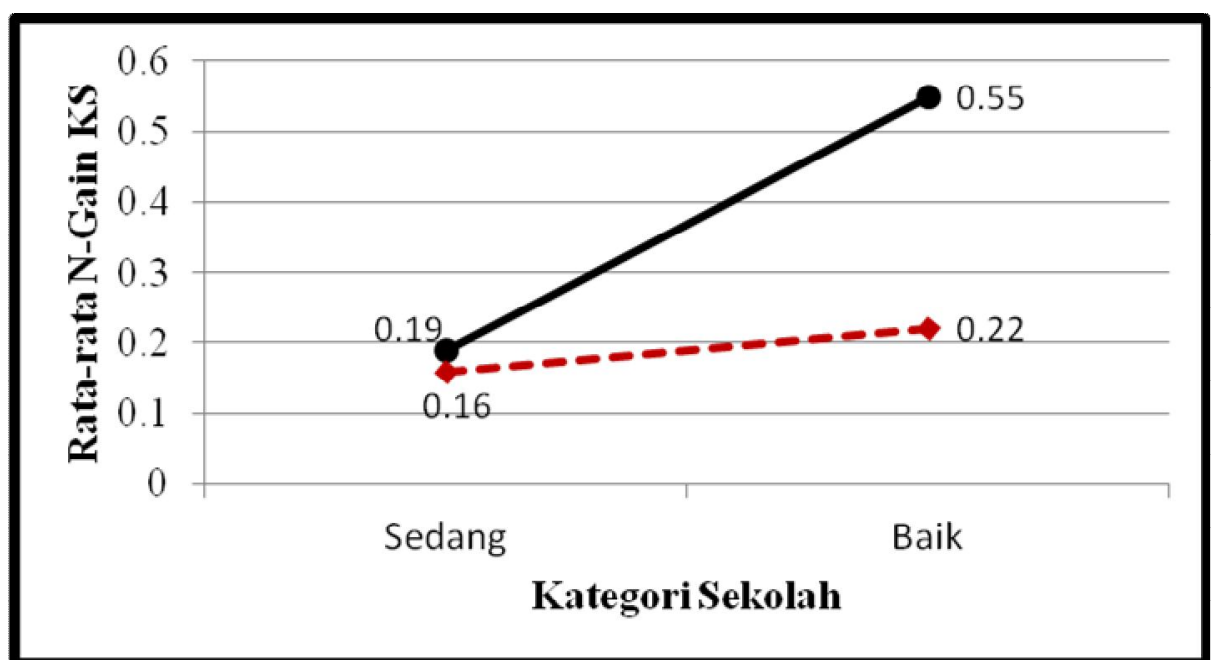

Gambar 5. Rata-rata N-Gain Kemampuan Spasial (KS) Siswa Ditinjau dari Kategori Sekolah dan Pendekatan Pembelajaran

Tabel 4. Uji Perbedaan dan Interaksi antara Pendekatan Pembelajaran dan Kemampuan Awal Matematika (KAM) Siswa terhadap Peningkatan Kemampuan Spasial (KS) Siswa

\begin{tabular}{ccccccc}
\hline Sumber Variasi & $\begin{array}{c}\text { Jumlah } \\
\text { Kuadrat }\end{array}$ & $\mathrm{db}$ & $\begin{array}{c}\text { Rata-rata } \\
\text { Kuadrat }\end{array}$ & $\mathrm{F}$ & Sig & Keputusan \\
\hline Pendekatan Pembelajaran & 0,335 & 1 & 0,335 & 9,83 & 0,002 & Tolak $\mathrm{H}_{0}$ \\
KAM & 0,341 & 2 & 0,170 & 4,93 & 0,008 & Tolak $\mathrm{H}_{0}$ \\
Interaksi & 0,030 & 2 & 0,015 & 0,45 & 0,641 & Terima $\mathrm{H}_{0}$ \\
Error & 4,972 & 146 & 0,340 & & & \\
Total & 18,21 & 152 & & & & \\
$\mathrm{H}_{0}: \alpha_{1}=\alpha_{2}=0$ & lawan & $\mathrm{H}_{1}$ & $:$ salah satu $\alpha_{i} \neq 0 ; \mathrm{i}=1,2$ & \\
$\mathrm{H}_{0}: \beta_{1}=\beta_{2}=\beta_{3}=0$ & lawan & $\mathrm{H}_{1}$ & $:$ salah satu $\beta_{i} \neq 0 \quad ; \mathrm{i}=1,2,3$ & \\
$\mathrm{H}_{0}: \alpha_{i} \beta_{j}=0$ & lawan & $\mathrm{H}_{1}$ & $:$ paling sedikit satu pasangan $: \alpha_{i} \beta_{j} \neq 0 ; \mathrm{i}=1,2 ; \mathrm{j}=1,2,3$.
\end{tabular}

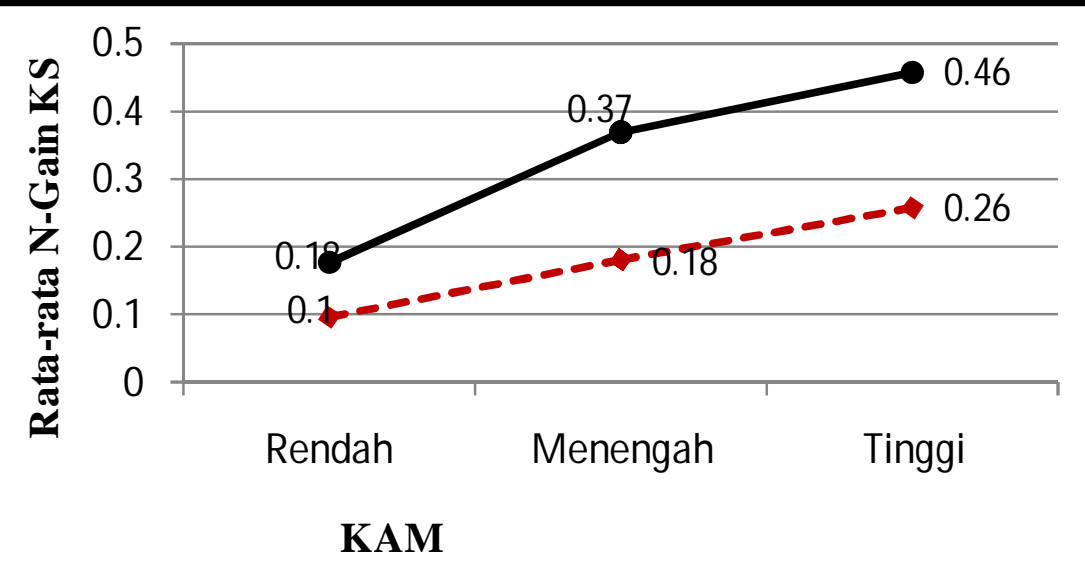




\section{Gambar 6. Peningkatan Kemampuan Spasial (KS) Siswa Ditinjau dari Kemampuan Awal Matematika (KAM) dan Pendekatan Pembelajaran}

Tabel 5. Uji Nyata Perbedaan (Uji Post Hoc)Peningkatan Kemampuan Spasial (KS) Siswa antarkelompok KAM

\begin{tabular}{lcccc}
\hline \multicolumn{1}{c}{$\begin{array}{c}\text { Antar } \\
\text { KAM }\end{array}$} & $\begin{array}{c}\text { Beda } \\
\text { Rata-rata }\end{array}$ & $\begin{array}{c}\text { Simpangan } \\
\text { Baku }\end{array}$ & Sig & Keputusan \\
\hline Tinggi - Menengah & 0,100 & 0,045 & 0,027 & Tolak $\mathrm{H}_{0}$ \\
Tinggi - Rendah & 0,224 & 0,069 & 0,002 & Tolak $\mathrm{H}_{0}$ \\
Menengah - Rendah & 0,124 & 0,058 & 0,034 & ${\text { Tolak } \mathrm{H}_{0}}$ \\
\hline
\end{tabular}

$\mathrm{H}_{0}$ : tidak terdapat perbedaan peningkatan kemampuan spasial (KS) yang signifikan antarkelompok KAM

Jadi, dapat dilihat bahwa kemiringan grafik pendekatan pembelajaran Matematika Realistik tidak lebih curam dibandingkan dengan kemiringan grafik pendekatan pembelajaran secara konvensional. Bahkan pada interval antara KAM menengah dan tinggi, kedua grafik hampir sejajar. Hal ini menunjukkan bahwa perbedaan peningkatan kemampuan spasial (KS) siswa tidak signifikan ditinjau dari interaksi antara pendekatan pembelajaran dan kelompok KAM siswa. Hal ini bermakna tidak ada pengaruh bersama antara pendekatan pembelajaran dan kelompok KAM siswa terhadap peningkatan kemampuan spasial siswa. Pendekatan pembelajaran dan kelompok KAM siswa saling independen terhadap peningkatan kemampuan spasial siswa.

\section{Uji Beda Lanjut (Post Hoc Test) Perbedaan Peningkatan Kemampuan Spasial (KS) Sis- wa}

Untuk mengetahui pasangan kelompok KAM (tinggi, menengah, rendah) yang paling dominan mempengaruhi peningkatan kemampuan spasial (KS) siswa dilakukan uji beda lanjut (post hoc) dengan menggunakan anova dua arah. Ringkasan hasil uji post hoc untuk peningkatan kemampuan spasial (KS) siswa ditinjau dari setiap pasangan kelompok KAM diberikan pada Tabel 5 .

Jadi, dapat dilihat bahwa nilai probabilitas (sig) untuk perbedaan peningkatan kemampuan spasial (KS) siswa antar kelompok KAM tinggi dan menengah sebesar 0,027 lebih kecil dari 0,05 sehingga diputuskan untuk menolak
$\mathrm{H}_{0}$. Penolakan $\mathrm{H}_{0}$ juga terjadi antar kelompok KAM tinggi dan rendah serta antar kelompok KAM menengah dan rendah. Ini berarti bahwa terdapat perbedaan peningkatan kemampuan spasial (KS) siswa yang signifikan antara kelompok KAM tinggi dan menengah, antara kelompok KAM tinggi dan rendah, serta antara kelompok KAM menengah dan rendah.

\section{PENUTUP}

Hasil Penelitian menunjukkan bahwa pendekatan pembelajaran matematika realistik pada topik geometri dengan bantuan komputer program cabri 3-D dapat meningkatkan kemampuan spasial siswa di sekolah berkategori baik dan sedang. Demikian juga pendekatan pembelajaran Matematika realistik dapat meningkatkan kemampuan spasial siswa yang memiliki latar belakang kemampuan awal matematika tinggi, menengah dan rendah. Selain itu terdapat pengaruh bersama antara pendekatan pembelajaran dan kategori sekolah terhadap peningkatan kemampuan spasial siswa.

\section{UCAPAN TERIMA KASIH}

Pada kesempatan ini penulis menyampaikan penghargaan dan terima kasih yang setinggi-tingginya kepada Prof. Jozua Sabandar, M.A. Ph.D., Prof. Dr. Didi Suryadi, M.Ed., serta Prof. Dr. Darhim, M.Si, yang telah membantu penulis menyempurnakan hasil penelitian ini. Akhirnya penulis juga menyampaikan terimakasih yang tak terhingga kepada semua pihak yang telah membantu sampai selesainya naskah tulisan ini. 


\section{DAFTAR PUSTAKA}

Alias, M.; Black, T. R. dan Gray D., E. 2002. "Effect of Instruction on Spatial Visualization Ability in Civil Engineering Students" dalam International Education Journal, III (1):1-12.

Anh, Le, T. 2006. Applying Realistic Mathematics Education in Vietnam: Teaching Middle School Geometry. Disertasi tidak diterbitkan. Potsdam: Universitat Potsdam.

Arifin, Z. 2008. Meningkatkan Motivasi Berprestasi, Kemampuan Pemecahan Masalah dan Hasil Belajar Siswa Kelas IV SD melalui Pembelajaran Matematika Realistik dengan Strategi Kooperatif di Kabupaten Lamongan. Disertasi tidak diterbitkan. Bandung: PPs UPI Bandung.

Asmida. 2009. Meningkatkan Kemampuan Penalaran dan Komunikasi Matematis Siswa SMP melalui Pendidikan Realistik. Tesis tidak diterbitkan. Bandung: PPs UPI Bandung.

Barke, H. D. dan Engida, T. 2001. "Structural Chemistry and Spatial Ability in Different Cultures" dalam Research and Practice in Europe. Vol. 2, no.3 pp.227239.

Chacon, I. M. 2008. Student's Attitudes to Mathematics and Technology Comparative Study Between the United Kingdom and Spain. London: City University.

Eriadi. 2008. Penerapan Pendekatan Pendidikan Matematika Realistik untuk Meningkatkan Kemampuan Pemahaman Matematis Siswa SMP. Tesis tidak diterbitkan. Bandung: PPs UPI Bandung.

Giaquinto. 2007. Visual Thinking in Mathematics An epistemological study. New York: Oxford University Press.
Hannafin, R. D.; Mary, P. Truxaw; Jennifer, R. V.; dan Yingjie, L. 2008. Effects of Spatial Ability and Instructional Program on Geometry Achievement. Connecticut: University of Connecticut.

Hidayat, E. 2009. Peningkatan Kemampuan Komunikasi Matematik dan Kemandirian Belajar Siswa dengan Menggunakan Pendidikan Matematika Realistik. Tesis tidak diterbitkan. Bandung: PPs UPI Bandung.

Johnson. 2006. Attitude or Anxiety: Mathematics Disposition of High School Algebra I. Student's. Tesis tidak diterbitkan.: Friends University

National Academy of Science. 2006. Learning to Think Spatially, Washington DC: The National Academics Press.

NCTM. 2000. Handbook of Research on Mathematics Teaching and Learning, Editor: Douglas A. Grows. USA: Macmillan Library Reference.

Nemeth, B. 2007. "Measurement of the Development of Spatial Ability by Mental Cutting Test" dalam Annales Mathematicae et Informaticae, (34): 123-128.

Rafi, A. dan Samsudin, K. Anuar. 2007. "The Relationships of Spatial Experience, Previous Mathematics Achievment, and Gender with Perceived Ability in Learning Engineering Drawing" dalam Journal of Technology Education. (XVIII) (2): 53-67.

Republika On Line. Maret, 2008. Melihat Dari Mata Pengamat Dunia, hlm. 1.

Ruseffendi, E. T. 2005. Dasar-Dasar Penelitian Pendidikan dan Bidang Non Eksakta Lainnya. Bagi para Peneliti, Penulis Skripsi, Penulis Tesis, Penulis Disertasi, Dosen Metode Penelitian, dan Mahasiswa. Bandung: Tarsito. 
Schackow. 2005. High School Student's Attitudes Toward Mathematics. Academic Exchange Quarterly.

Strong, S. dan Roger, S. 2002. "Spatial Visualization: Fundamentals and Trends in Enginering Graphics" dalam Journal of Industrial Technology, XVIII (1): 1-6.
Sulastri, Y. L. 2009. Meningkatkan Kemampuan Komunikasi Matematis Melalui Pembelajaran dengan Pendekatan Pendidikan Matematika Realistik siswa Sekolah Menengah Pertama di Kabupaten Bandung. Tesis tidak diterbitkan. Bandung: PPs UPI Bandung. 